\title{
Trait-based surveillance of flood channel effects on the River Thames
}

\author{
Les Ruse'
}

Ruse L. 2012. Trait-based surveillance of flood channel effects on the River Thames. Fauna norvegica 31: $109-116$.

An artificial anabranch was opened to the main River Thames by the end of 2001. Chironomid pupal exuviae have been sampled from sites along the main river since 1977 including sites above and below the anabranch. Two sites on the anabranch have also been surveyed since its opening. Long-term surveillance of the chironomid assemblage prior to construction of the anabranch provided a reference state by which its impact could be assessed. Feeding and habitat preferences were attributed to chironomid taxa while additional environmental -tolerance traits were derived from the long-term data of the Thames. Canonical Correspondence Analysis, with spatial variation partialled out, was used to select temporal environmental variables explaining chironomid taxa distribution. Taxa with significant $t$-values in the regression with selected environmental variables were then included in the subsequent analysis of variance of traits by General Linear Modelling. From 1977 up to 2001 lower Thames sites, above and below the anabranch, showed no significant changes in any of the traits investigated. Four surveys from 2002 to 2009 have revealed some significant changes downstream of the anabranch, both in comparison with before-construction and between sites. These changes suggest the anabranch is providing a sink for poor-quality sediments. Immediately downstream of the anabranch fine sedimentdwelling chironomids have declined within the Thames, chironomids sensitive to ammonia have increased while chironomids tolerant of organic pollution have decreased.

doi: 10.5324/fn.v31i0.1360. Received: 2011-10-04. Accepted: 2012-03-28.

Published on paper and online: 2012-10-17.

Keywords: Anabranch, CPET, Trait analysis, Feeding Group, Discharge

1. APEM Ltd., FBA East Stoke, Wareham, Dorset BH20 6BB, UK

Corresponding author: Les Ruse

E-mail:les.ruse@roehampton.ac.uk

\section{INTRODUCTION}

An $11.6 \mathrm{~km}$ River Thames flood alleviation channel, named the Jubilee River, was constructed around Maidenhead west of London (Figure 1) and opened to the main river in October 2001 (Ruse 2002). There has been surveillance of up to 16 sites along the non-tidal River Thames since 1977 when Wilson (1980) classified British rivers using the Chironomid Pupal Exuvial Technique (CPET). This survey has been repeated many times, and extended to include more sites, to provide baseline data for a proposed river transfer, reservoir, flood channel or any other modification. Ruse \& Davison (2000) reported there were no significant differences in proportions of fine-sediment dwelling chironomids or feeding types immediately above and below the intended flood channel. Subsequently, eight more CPET surveys of the River Thames have been repeated up to 2009, with four surveys since the flood channel was connected to the Thames. In addition, two sites on the flood channel have been included within the last three surveys. The long-term stability of chironomid composition at Thames sites upstream and downstream of the Jubilee River provided a control for subsequent assessment of the impact of the channel on the main river.

CPET provides a method of water quality assessment that largely overcomes the problems associated with monitoring large, deep rivers (Ruse \& Wilson 1984; Wilson \& Wilson 1985; Ruse et al. 2000; Raunio \& Antilla-Huhtinen 2008) particularly long-term studies (Ruse \& Davison 2000). Samples of floating debris trapped behind in-stream vegetation or artifacts such as lock gates and sluices, contain an integrated collection of pupal exuviae accumulated over the previous two or three days (Wilson \& Bright 1973; Ruse 1993). These exuviae belong to chironomids that could have emerged from any of the available 
habitats a short distance upstream of the sampling point. The assemblage of species succeeding in maintaining a population at a river site will reflect the physical and chemical quality of the sediments and the overlying water.

Specific changes in taxa composition over years may occur for a variety of reasons other than a change in the ecological functioning of the Thames. For a mechanical, multispecies biomonitoring of human impact; across-taxa traits provide a robust tool independent of topographical, geographical, geological and seasonal change in species composition (Charvet et al. 2000; Bêche et al. 2006; McGill et al. 2006; Horrigan \& Baird 2008). Chironomid taxa data in this study have been translated into definable, long-term functional traits such as feeding groups or significant adaptations to river flow or chemical composition. Comparison was then made between proportions of these functional groups before and after the flood channel became an anabranch of the River Thames.

\section{METHODS}

\section{Study Area and Sampling}

The flood channel has a mean width of $45 \mathrm{~m}$ and a maximum depth of $5 \mathrm{~m}$. There is a legal requirement for a minimum flow of water through the channel to the River Thames of $5 \mathrm{~m}^{3} \mathrm{~s}^{-1}$ at all times to prevent problems of stagnation. Beside weirs at either end of the flood channel there are three more weirs along its course.

Data from the upstream site and the next four sites downstream of the anabranch were analysed to assess the effects on the Thames. Additionally, sites by two of the weirs were established on the flood channel from 2003 for comparison (Figure 1). To determine which measured environmental variables significantly explained chironomid taxa variation within the non-tidal Thames all 16 sites were analysed.

Chironomid pupal exuviae were sampled using a 250 $\mu \mathrm{m}$ mesh net attached to a circular or triangular frame on an extendable pole to collect floating debris accumulating behind

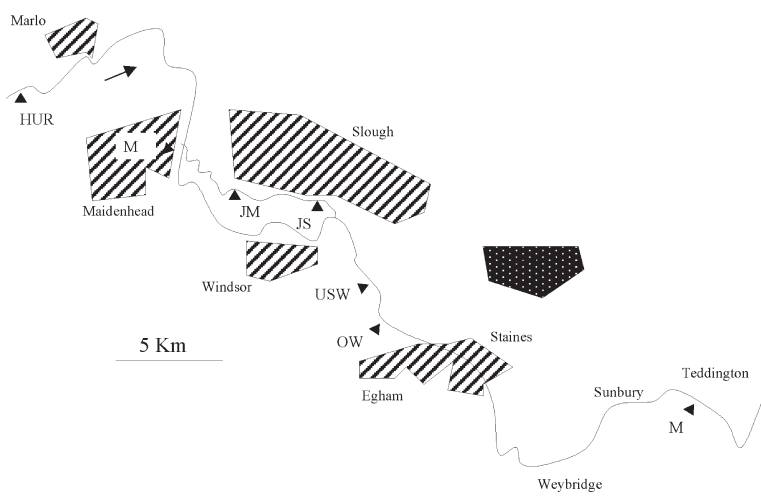

Figure I. Lower River Thames and Jubilee River (JM, JS) sampling sites indicated by solid triangles. obstacles at the river margins or lock and sluice gates. For each survey sites were sampled three times in different months between April and October as this yielded at least $80 \%$ of the available genera (Ruse \& Wilson 1984). Approximately 200 pupal exuviae were subsampled randomly from each collection and identified, at least to genus using the key of Wilson \& Ruse (2005). Amalgamated sample data for each site therefore provided a minimum of 600 pupal exuviae for any survey. The abundance of each taxon collected at a site was recorded as a percentage of the total number of exuviae collected from that site over the three samples of a survey. All analyses were performed on percentage data to accommodate any differences in sample size.

Chemical data, collected monthly or fortnightly, were available for all 16 sites along the River Thames for the period 1977 - 2002. Annual mean and extreme values for $\mathrm{BOD}_{\mathrm{ATU}}$, DO, unionised ammonia $\left(\mathrm{NH}_{3}\right)$, TON and orthophosphate were available across the full data set. Maximum values were taken as extreme for all determinands except DO, for which minimum values were used. Chemical data for each survey covered the twelve months up to and including the last month of pupal exuviae collection. Details of the chemical sampling points can be found in Ruse \& Davison (2000). Annual mean daily discharges (October to September) for every chironomid sampling site were also available over this period. Annual flow data into the tidal Thames were also available and used to compare discharge before and after channel construction. In addition to these annually variable measurements, data on altitude, slope, distance downstream of river source, channel mean depth and width were also recorded for each site. Environmental data that were not normally-distributed were normalised; mean concentrations of unionised ammonia, mean TON, mean and maximum orthophosphate, discharge and slope were all square-root transformed while maximum concentrations of unionised ammonia were $\log _{10(x+0.1)}$ transformed.

\section{Multivariate analysis}

Direct gradient relationships between chironomid taxa (fourthroot percentage, $4 \sqrt{ } \%$ ) and environmental data were investigated by unimodal Canonical Correspondence Analysis (CCA, ter Braak \& Šmilauer 1998) using biplot-scaling with emphasis on inter-species distances. Environmental data were standardised to have a zero mean and unit variance to account for arbitrary variations in units of measurement. Species occurring in less than one fifth of surveys of the most frequent species had their abundance downweighted in proportion to their frequency. Environmental variables significantly related to species data were selected by forward stepwise regression based on the observed $F$-ratio compared to that obtained by running 999 Monte Carlo random permutations of the same data. A covariable file was used to restrict permutations so that repeated sampling of the same sites did not contribute to the significance of the relationship with environmental variables. Probability levels of significance began at $\alpha=0.05$ for selection of the first 
variable but were then lowered for Bonferroni inequality with $P=\alpha / \mathrm{n}$, where $\mathrm{n}$ is the variable rank, this protected against inclusion of redundant variables (Manly 1991).

As in conventional regression analysis, covariables can be used in CCA to account for obvious or unwanted variation. The residual variation may then be investigated by partial canonical correspondence analysis (PCCA). PCCA was used to investigate temporal variation in biological data so that spatial variation of environmental variables, such as discharge, was removed. Spatial variation response (z) was efficiently modelled by supplying variables derived from a cubic trend surface regression equation (Legendre, 1990). Forward stepwise regression selected terms from the full quadratic equation of site longitude (x) and latitude (y) which significantly explained two-dimensional spatial variation among chironomid data, tested by unrestricted Monte Carlo permutations (Ruse \& Davison 2000). The resulting quadratic spatial model for all River Thames sites was:

$$
z==b_{1} x+b_{2} y+b_{3} x^{2}+b_{4} x^{2} y
$$

whereas, for the five lower Thames and two Jubilee River sites the selected model was:

$$
\begin{aligned}
& z=b_{1} x+b_{2} x^{2} \\
& \text { where } b_{n}=\text { estimated constants }
\end{aligned}
$$

Along the whole Thames, spatial variation in the chironomid data was explained by longitudinal and latitudinal coordinates, while for the lower Thames longitude alone was required.

\section{Trait analysis}

The two covariable files described above provided tools for partitioning temporal and spatial variance among biological data (Rodriguez \& Magnan 1995). The spatial model covariable was also used to obtain $t$-values of the regression of taxa on the temporal variation of specific environmental variables (ter Braak \& Looman 1994; Ruse 1994). Ruse \& Davison (2000) used $t$ values derived this way to provide lists of indicator taxa related significantly positively and negatively to Discharge and TON in the River Thames during 1977-1997. This analysis was repeated for all Thames sites from 1977 until 2002 to discover indicator taxa significantly related to forwardly-selected variables. These empirical, explanatory power-tested relationships were then treated as additional taxon traits for temporal comparison (before and after) effects of the construction of the anabranch of the Thames by univariate analysis.

Percentage data were normally-distributed and did not require transformation. The following traits were reported for each taxon in Wilson \& Ruse (2005) and recorded here within the Appendix. Taxa were classified into feeding groups; predators, grazers, detritivores, filter-feeders, parasites/commensals and also according to whether they preferred fine sediments in which they burrowed or lived on coarse sediments (stones,
Table I. Survey mean annual discharge $\left(\mathrm{m}^{3} \mathrm{sec}^{-1}\right)$ ranked over 126 years.

\begin{tabular}{cccc}
\hline Rank & Survey & Flow & \% Average \\
\hline 24 & 1977 & 88.3 & 135 \\
54 & 1978 & 73.1 & 112 \\
65 & 1986 & 63.4 & 97 \\
122 & 1992 & 18.8 & 29 \\
43 & 1993 & 77.5 & 119 \\
30 & 1994 & 83.9 & 128 \\
52 & 1995 & 73.6 & 113 \\
125 & 1997 & 12.4 & 19 \\
91 & 1998 & 47.9 & 73 \\
51 & 1999 & 74.2 & 114 \\
58 & 2000 & 70.4 & 108 \\
1 & 2001 & 142.1 & 217 \\
74 & 2002 & 58.6 & 90 \\
31 & 2003 & 83.0 & 127 \\
13 & 2007 & 98.7 & 151 \\
71 & 2009 & 59.5 & 91 \\
\hline
\end{tabular}

walls, plants). Further traits were derived within this study as explained above. For analysing variance of a single attribute in both space and time it was necessary to use a General Linear Model (GLM) rather than ANOVA because there were unequal numbers of surveys of each site (unbalanced). The model tested was response variable, trait, resulting from the crossed factors; site, event (before and after channel) and their interaction. Differences in traits between sites, both before and after the construction of the anabranch, were not accepted unless confirmed by Bonferroni simultaneous pairwise comparisons of $95 \%$ confidence intervals of site means. Differences in traits between the two Jubilee River sites and the five Thames sites post-construction could be tested by one-way ANOVA and confirmed by conservative Tukey-Kramer HSD (honestly significant difference) simultaneous pairwise comparisons of $95 \%$ confidence intervals of site means.

\section{RESULTS}

There were 133 amalgamated samples ( 3 visits per site) taken along the non-tidal Thames during 1977-2002 contributing 109 chironomid taxa for analysis with contemporary environmental data. Environmental variables uniquely explained $22.0 \%$ of taxa variation between surveys while an additional 15.8\% was explained by taxa variation between sites. After fitting for spatial variation, forwardly selected explanatory temporal variables were; annual mean daily discharge, max BOD, mean DO, max $\mathrm{NH}_{3}$ and mean TON. Significant $t$-values of the regression of temporal variation of these variables with 
any chironomid taxa, both positive and negative, provided additional traits for assessing the temporal effects of the flood channel in the lower Thames (Appendix).

Comparing mean annual runoff from the non-tidal River Thames during the hydrological years from October 1883 until September 2009, the survey in 2001 experienced the

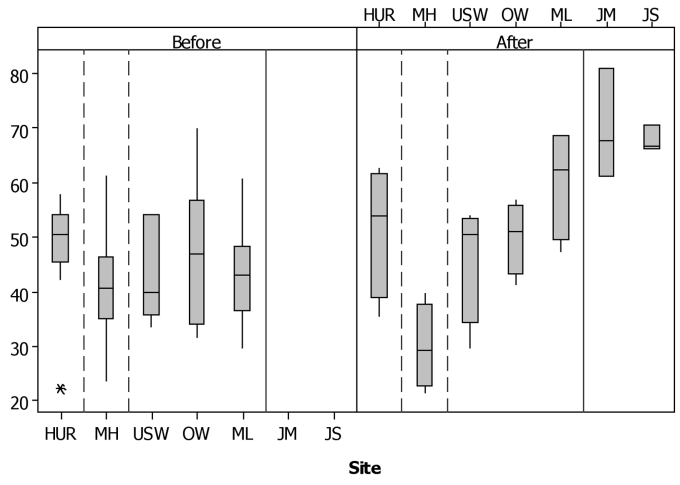

Figure 2. Proportions of fine sediment dwellers before and after flood channel connected. Lower, middle and upper limit of box is first (q1), second (median) and third quartile(q3) respectively. Lower whisker limit is the lowest value within q1 - 1.5(q3-q1). Upper whisker limit is the highest value within $\mathrm{q} 3+1.5(\mathrm{q} 3-\mathrm{q} 1)$. Asterisk is an outlier.

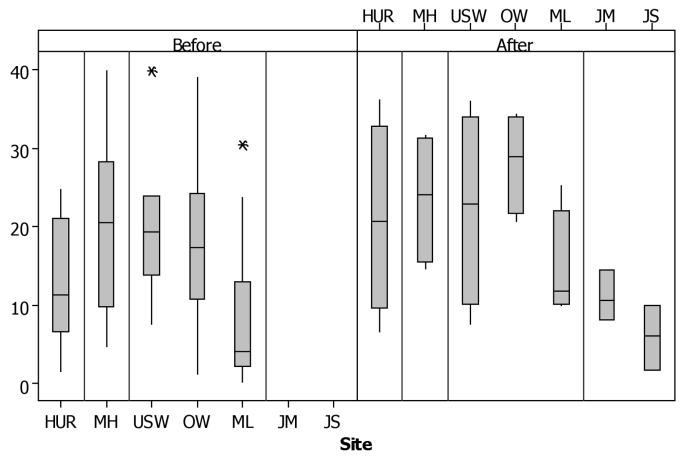

Figure 3. Proportions of ammonia sensitive chironomids before and after flood channel connected. Symbols defined as for Figure 2.

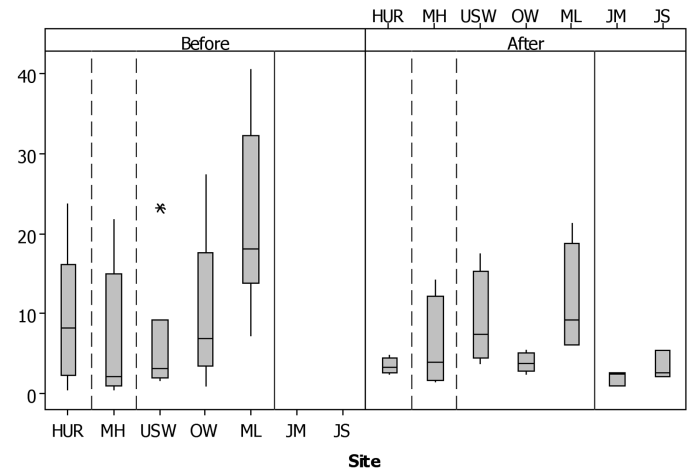

Figure 4. Proportions of BOD tolerant chironomids before and after flood channel connected. Symbols defined as for Figure 2. highest flows in all 126 years (Table 1). Surveys following the opening of the flood channel in October 2001 had flows comparable to the long term average except that of $2007\left(13^{\text {th }}\right.$ highest discharge). The lowest annual mean flow experienced by chironomid larvae in this study was the 1997 survey, second only to the lowest discharge on record in the hydrological year ending September 1976. The average of discharge during surveys prior to the opening of the flood channel was $69 \mathrm{~m}^{3} \mathrm{~s}^{-1}$ while the four subsequent surveys averaged $75 \mathrm{~m}^{3} \mathrm{~s}^{-1}$.

\section{Trait Analysis}

A box and whisker plot is used to graphically compare the proportion of fine-sediment dwelling chironomids at sites before (1977-2001, 12 surveys) and after (2002-2009, 4 surveys) the anabranch was opened to the main River Thames (Figure 2). In a Bonferroni multiple comparison of fine-sediment dwellers before and after channel construction there were no significant differences when considering all Lower Thames sites collectively. Before construction of the anabranch there were no differences between Thames sites, this was the case for all traits analysed. Post-construction, the first site after the flood channel at Maidenhead (MH) had significantly less fine-sediment dwellers than Hurley (HUR; $\mathrm{P}=0.031$ ), Old Windsor (OW; $\mathrm{P}=0.049)$ and Molesey (ML; 0.006) and there was a consistent trend of increasing proportions of fine sediment dwellers downstream of the anabranch. In a one-way ANOVA fine-sediment dwellers at both flood channel sites were significantly higher than at Maidenhead while at Marsh Weir (JM) sediment dwellers were also significantly higher than at Upstream Windsor (USW; $\mathrm{r}^{2}=71.2 \%, \mathrm{P}<0.001$ ).

In terms of predatory chironomids there were no significant differences at any site after constructing the flood channel compared with before and there were no differences between sites, including those of the flood channel. Proportions of grazers also did not change significantly following the opening of the flood channel but there were significantly lower proportions of grazers at Marsh Weir than at Maidenhead $\left(\mathrm{r}^{2}=48.3 \%\right.$, $\mathrm{P}=0.033$ ). Using GLM there was a difference between sites across all surveys $\left(\mathrm{r}^{2}=23.5 \%, \mathrm{P}=0.043\right)$ due to Maidenhead having lower proportions of detritivores than Old Windsor but this was not confirmed by the conservative Bonferroni pairwise site comparisons. Post-construction proportions of detritivores were significantly lower at Maidenhead than at Molesey and both anabranch sites $\left(\mathrm{r}^{2}=59.9 \%, \mathrm{P}=0.004\right)$. There were no significant changes in proportions of filter-feeders between sites or before and after the anabranch. Percentage parasites/ commensals did not vary between sites but was significantly lower after the anabranch was built $\left(\mathrm{r}^{2}=18.9 \%, \mathrm{P}=0.047\right.$, Bonferroni confirmed) particularly at Upstream Windsor STW site, the first site below outflows from the anabranch returning to the main river.

Considering traits deduced from the long-term data of the River Thames, proportions of chironomids positively related to river discharge (rheophiles) across the five lower Thames 
sites did not change temporally across collective Thames sites but following channel construction they were significantly higher at Maidenhead compared with the most downstream site at Molesey $\left(\mathrm{r}^{2}=29.1 \%, \mathrm{P}=0.002\right)$. Chironomids negatively related to discharge have not changed temporally or spatially at any Thames site since 1977. There were also no changes temporally or spatially in proportions of chironomids either positively or negatively related to river concentrations of TON. There has been a been a significant increase of ammoniasensitive chironomids in the main River Thames since the flood channel was opened $\left(\mathrm{r}^{2}=22.6 \%, \mathrm{P}=0.049\right)$. In a one-way ANOVA the anabranch Slough Weir site (JS) had significantly lower proportions of ammonia-sensitive chironomids than Old Windsor downstream $\left(\mathrm{r}^{2}=46.5 \%, \mathrm{P}=0.043\right.$ Tukey-Kramer confirmed, Figure 3). BOD-tolerant chironomids in the main River were collectively significantly greater before than after the anabranch $(\mathrm{P}=0.046)$ as well as being greater at Molesey than both Hurley $(\mathrm{P}=0.036)$ and Maidenhead $(\mathrm{P}=0.040)$ following channel construction (Figure 4). There has been no significant change in BOD-sensitive chironomids before or after the flood channel existed, or between sites.

\section{DISCUSSION}

A combination of a priori traits and empirical, realised niche traits have been used to analyse data collected over 33 years. This has provided a robust, definable, repeatable method of monitoring change in the River Thames, now and in the future. These traits would be most relevant to the ecology of the final larval instars as these relate to subsequent successful emergence. It is acknowledged that earlier instars can have different feeding modes from later instars of the same species due to mouth gape differences and possibly to avoid conspecific competition (Ruse 1994).

It was necessary with these routinely collected, long-term data, from approximately $250 \mathrm{~km}$ of river to partition variation in the chironomid fauna so that temporal variation between surveys could be investigated and used to select trait preferences independently of downstream variation which could include functional change such as allocthonous processing replacing autocthonous sources. Typically, downstream sites can be expected to have higher discharge (volume), greater loads of nutrients and pollutants as well as different habitats. After removing spatial differences, the residual variation between surveys was related to current, organic and nutrient loads at the same site. This overcame the confounding influence of natural spatial gradients that can hinder the interpretation of traits in relation to human disturbance (Menezes et al. 2010). Multivariate analysis of long-term data has here provided in situ biomonitoring of the net effect of multiple stressors that is often ignored in catchment management plans (Townsend et al. 2008 )

Temporal variation in BOD, TON, DO and $\mathrm{NH}_{3}$ were significant explanatory variables of chironomid distribution. During early surveys there were some particularly high concentrations of $\mathrm{NH}_{3}$ and low DO in the upper Thames and at Teddington (Ruse \& Davison 2000), the most downstream site. Teddington was excluded from assessing the flood channel because of this confounding influence as well as tidal encroachment. The surveys undertaken from 1977 up to 2009 have witnessed almost the full range of discharge experienced by the Thames since 1883, from the second lowest discharge in 1996/7 to the highest in 2000/1. Discharge during survey years after the opening of the flood channel was considered representative of the long-term average. Chironomid taxa identified from these long-term data as significantly related to temporal flow variation could supplement a taxonomic macroinvertebrate river flow index as used in Britain (Extence et al. 1999).

In the main river sites the addition of the anabranch has resulted in a significant increase in ammonia-sensitive chironomids and a decrease in BOD-tolerant chironomids. The only feeding group significantly affected was a decrease in parasitic/commensal chironomids. Dahl \& Johnson (2004) found that parasites, as a percentage of the community, significantly increased with increasing organic pollution in Swedish streams. Other traits have significantly changed between sites following the connection with the flood channel, whereas before connection there were no differences found between any of these sites. River Thames fine-sediment dwellers and detritivores decreased immediately downstream of the take-off point of the flood channel at Maidenhead while taxa positively related to discharge increased. In contrast to Maidenhead and Thames sites downstream, the two anabranch sites had lower proportions of ammonia-sensitive, rheophilic and grazing chironomids while having higher proportions of fine-sediment dwellers and detritivores. A review of trait studies by Statzner \& Bêche (2010) suggests grazers are sensitive to channelisation as well as reductions in flow and oxygen while collector-gatherers react positively. The responses of chironomids in terms of traits suggests that the flood channel has had a positive influence on the downstream Thames sites by acting as a sink for poor-quality sediments, particularly towards the downstream end of this anabranch. This would be expected from the results of McGinness \& Arthur (2011) although they studied Australian anabranches intermittently connected to the main river. The weirs within the flood channel add further complexity to the catchment, reducing nutrient spiral length and ecosystem 'leakiness' (Rapport et al. 1985) to the benefit of the highly managed and organically-stressed River Thames which lacks an extensive natural flood plain.

Functional trait analysis, supported by these longterm chironomid population data, provide a suitable basis for continuing vigilance of the River Thames as future anthropogenic impacts arrive in the form of a river-regulating reservoir, river transfer and climate change. 


\section{ACKNOWLEDGMENTS}

Gratitude to Ron Wilson for inaugurating Thames CPET surveys. Since then I have had assistance from Mark Davison, Clare Gladdy, Ina Stone and Peter Langton. Data were kindly supplied by the Environment Agency. Thanks to Thienemann, not only for originally suggesting the collection of chironomid pupal exuviae but also for conceiving that increased physical and chemical stress selected for traits (Statzner \& Bêche 2010).

\section{REFERENCES}

Bêche LA, McElravy EP, Resh VH. 2006. Long-term seasonal variation in the biological traits of benthic-macroinvertebrates in two Mediterranean-climate streams in California, U.S.A. Freshwater Biology 51: 56-75.

Charvet S, Statzner B, Usseglio-Polatera P, Dumont B. 2000. Traits of benthic macroinvertebrates in semi-natural French streams: an initial application to biomonitoring in Europe. Freshwater Biology 43: 277-296.

Dahl J, Johnson RK. 2004. A multimetric macroinvertebrate index for detecting organic pollution of streams in southern Sweden. Archiv für Hydrobiologie 160: 487- 513.

Extence CA, Balbi DM, Chadd RP. 1999. River flow indexing using British benthic macroinvertebrates: a framework for setting hydroecological objectives. Regulated Rivers 15: 543574.

Horrigan N, Baird DJ. 2008. Trait patterns of aquatic insects across gradients of flow-related factors: a multivariate analysis of Canadian national data. Canadian Journal of Fisheries \& Aquatic Sciences 65: 670-680.

Legendre P. 1990. Quantitative methods and biogeographic analysis In: Garbary D.J, South GR. (eds.). Evolutionary Biogeography of the Marine Algae of the North Atlantic, N.A.T.O. ASI series G22, Springer-Verlag, Berlin. pp. 9-34.

Manly BFJ. 1991. Randomization and Monte Carlo methods in biology. Chapman and Hall, London, 281 p.

McGill BJ, Enquist BJ, Weiher E, Westoby M. 2006. Rebuilding community ecology from functional traits. TRENDS in Ecology \& Evolution 21: 178-185.

McGinness HM, Arthur AD. 2011. Carbon dynamics during flood events in a lowland river: the importance of anabranches. Freshwater Biology 56: 1593-1605.

Menezes S, Baird DJ, Soares AMVM. 2010. Beyond taxonomy: a review of macroinvertebrate trait-based community descriptors as tools for freshwater biomonitoring. Journal of Applied Ecology 47: 711-719.

Rapport DJ, Regier HA, Hutchinson TC. 1985. Ecosystem behavior under stress. The American Naturalist 125: 617-640.

Raunio J, Anttila-Huhtinen M. 2008. Sample size determination for soft-bottom sampling in large rivers and comparison with the chironomid pupal exuvial technique (CPET). River Research \& Applications 24: 835-843

Rodriquez MA, Magnan P. 1995. Application of multivariate analyses in studies of the organization and structure of fish and invertebrate communities. Aquatic Sciences 57: 199-216.

Ruse LP. 1993. Chironomid distribution in the River Pang in relation to environmental variables. PhD Thesis; University of Bristol; $365 \mathrm{p}$.

Ruse LP. 1994. Chironomid microdistribution in gravel of an English chalk river. Freshwater Biology 32: 533-551.

Ruse L. 2002. Colonisation of gravel lakes by Chironomidae. Archiv für Hydrobiologie 153: 391- 407.

Ruse L, Davison M. 2000. Long-term assessment of chironomid taxa structure and function in the River Thames. Regulated Rivers 16: 113-126.

Ruse LP, Herrmann SJ, Sublette JE. 2000. Chironomidae (Diptera) species distribution related to environmental characteristics of the metal-polluted Arkansas River, Colorado. Western North American Naturalist 60: 34-56.

Ruse LP, Wilson RS. 1984. The monitoring of river water quality within the Great Ouse basin using the Chironomid Exuvial Analysis Technique. Water Pollution Control 83: 116-135.

Statzner B, Bêche LA. 2010. Can biological invertebrate traits resolve effects of multiple stressors on running water ecosystems? Freshwater Biology 55: 80-119.

ter Braak CJF, Looman CWN. 1994. Biplots in reduced-rank regression. Biometrical Journal 36: 983-1003.

ter Braak CJF, Šmilauer P. 1998. CANOCO Reference Manual and User's Guide to Canoco for Windows: Software for Canonical Community Ordination (version 4). Microcomputer Power; Ithaca, New York; $352 \mathrm{p}$.

Townsend CR, Uhlmann SS, Matthaei CD. 2008. Individual and combined responses of stream ecosystems to multiple stressors. Journal of Applied Ecology 45: 1810-1819.

Wilson RS. 1980. Classifying rivers using chironomid pupal exuviae. In: Murray DA. (ed.). Ecology, Systematics, Cytology and Physiology, Pergamon Press, Oxford. pp. 209-216.

Wilson RS, Bright PL. 1973. The use of chironomid pupal exuviae for characterizing streams. Freshwater Biology 3: 283-302.

Wilson RS, Ruse LP. 2005. A guide to the identification of genera of chironomid pupal exuviae occurring in Britain and Ireland and their use in monitoring lotic and lentic freshwaters. Freshwater Biological Association Special Publication no. 13, Windermere, $176 \mathrm{p}$.

Wilson RS, Wilson SE. 1985. A survey of the distribution of Chironomidae of the River Rhine by sampling pupal exuviae. Hydrological Bulletin 18: 119-132. 
Appendix. Biological and ecological traits assigned to taxa.

\begin{tabular}{|c|c|c|c|c|c|c|c|c|c|c|c|c|c|c|}
\hline Taxa & Predator & Grazer & Detritivore & Filterer & Parasite & Sediment & Flow + & Flow- & $\mathrm{N}+$ & N- & $\mathrm{NH}_{3}+$ & $\mathrm{NH}_{3-}^{-}$ & $\mathrm{BOD}+$ & BOD- \\
\hline Clinotanypus nervosus & 1 & -- & -- & -- & -- & 1 & -- & -- & -- & -- & -- & -- & -- & -- \\
\hline Apsectrotanypus trifascipennis & 1 & -- & -- & -- & -- & 1 & -- & -- & -- & -- & -- & -- & -- & -- \\
\hline Macropelopia & 1 & -- & -- & -- & -- & 1 & -- & -- & -- & -- & -- & -- & -- & -- \\
\hline Macropelopia nebulosa & 1 & -- & -- & -- & -- & 1 & -- & 1 & -- & -- & -- & -- & -- & -- \\
\hline Procladius & 1 & -- & -- & -- & -- & 1 & -- & -- & -- & -- & 1 & -- & -- & -- \\
\hline Psectrotanypus varius & 1 & -- & -- & -- & -- & 1 & -- & -- & -- & -- & -- & -- & -- & -- \\
\hline Ablabesmyia & 1 & -- & -- & -- & -- & 1 & 1 & -- & -- & -- & -- & -- & -- & -- \\
\hline Ablabesmyia monilis & 1 & -- & -- & -- & -- & 1 & -- & -- & -- & -- & 1 & -- & 1 & -- \\
\hline Arctopelopia & 1 & -- & -- & -- & -- & 1 & -- & -- & -- & -- & -- & -- & -- & -- \\
\hline Conchapelopia & 1 & -- & -- & -- & -- & -- & -- & -- & -- & -- & -- & -- & -- & -- \\
\hline Conchapelopia melanops & 1 & -- & -- & -- & -- & -- & -- & -- & -- & -- & 1 & -- & -- & -- \\
\hline Rheopelopia & 1 & -- & -- & -- & -- & -- & 1 & -- & -- & -- & -- & 1 & -- & 1 \\
\hline Thienemannimyia & 1 & -- & -- & -- & -- & 1 & 1 & -- & -- & -- & -- & 1 & -- & 1 \\
\hline Tanypus & 1 & -- & -- & -- & -- & 1 & -- & -- & -- & -- & -- & -- & -- & -- \\
\hline Protanypus morio & 1 & -- & -- & -- & -- & 1 & -- & -- & -- & -- & -- & -- & -- & -- \\
\hline Potthastia & -- & -- & 1 & -- & -- & 1 & -- & -- & -- & -- & -- & -- & -- & -- \\
\hline Prodiamesa olivacea & -- & -- & 1 & -- & -- & 1 & -- & -- & -- & -- & -- & -- & -- & -- \\
\hline Brillia flavifrons & -- & 1 & -- & -- & -- & -- & -- & -- & -- & -- & -- & -- & -- & -- \\
\hline Brillia bifida & -- & 1 & -- & -- & -- & -- & -- & -- & -- & -- & -- & -- & -- & -- \\
\hline Cardiocladius fuscus & 1 & -- & -- & -- & -- & -- & -- & -- & -- & -- & -- & -- & -- & -- \\
\hline Cricotopus (Cricotopus) & -- & 1 & -- & -- & -- & -- & 1 & -- & 1 & -- & 1 & -- & -- & -- \\
\hline Cricotopus (C) bicinctus & -- & 1 & -- & -- & -- & -- & -- & -- & -- & 1 & -- & 1 & -- & 1 \\
\hline Cricotopus $(\mathrm{C})$ trifascia & -- & 1 & -- & -- & -- & -- & 1 & -- & -- & -- & -- & -- & -- & 1 \\
\hline Cricotopus (Isocladius) & -- & 1 & -- & -- & -- & -- & -- & 1 & 1 & -- & 1 & -- & 1 & -- \\
\hline Cricotopus (I) intersectus gp & -- & 1 & -- & -- & -- & -- & -- & -- & -- & -- & -- & -- & -- & -- \\
\hline Cricotopus (I) sylvestris & -- & 1 & -- & -- & -- & -- & -- & 1 & -- & 1 & -- & -- & -- & -- \\
\hline Diplocladius cultriger & -- & -- & 1 & -- & -- & 1 & -- & -- & -- & -- & -- & -- & -- & -- \\
\hline Eukiefferiella & -- & 1 & -- & -- & -- & -- & -- & -- & -- & -- & -- & -- & -- & -- \\
\hline Eukiefferiella claripennis & -- & 1 & -- & -- & -- & -- & -- & -- & -- & -- & -- & -- & -- & -- \\
\hline Heterotanytarsus apicalis & -- & -- & 1 & -- & -- & 1 & -- & -- & -- & -- & -- & -- & -- & -- \\
\hline Nanocladius & -- & 1 & -- & -- & -- & -- & -- & -- & -- & -- & -- & -- & -- & -- \\
\hline Nanocladius balticus & -- & 1 & -- & -- & -- & -- & -- & -- & -- & -- & -- & -- & -- & -- \\
\hline Orthocladius (Eudactylocladius) & -- & 1 & -- & -- & -- & -- & -- & -- & -- & -- & -- & -- & -- & -- \\
\hline Orthocladius (Pogo) consobrinus & -- & 1 & -- & -- & -- & -- & -- & -- & -- & -- & -- & -- & -- & -- \\
\hline Orthocladius (Euorthocladius) & -- & 1 & -- & -- & -- & -- & -- & -- & -- & -- & -- & -- & -- & -- \\
\hline Orthocladius (ss) & -- & 1 & -- & -- & -- & -- & 1 & -- & -- & -- & -- & -- & -- & -- \\
\hline Paracladius conversus & -- & 1 & -- & -- & -- & 1 & -- & -- & -- & -- & -- & -- & -- & -- \\
\hline Paratrichocladius rufiventris & -- & 1 & -- & -- & -- & -- & -- & 1 & 1 & -- & 1 & -- & 1 & -- \\
\hline Psectrocladius (ss) & -- & -- & 1 & -- & -- & 1 & -- & -- & -- & -- & -- & -- & -- & -- \\
\hline Psectrocladius (ss) barbimanus & -- & -- & 1 & -- & -- & 1 & -- & -- & -- & -- & -- & -- & -- & -- \\
\hline Psectrocladius (Allo) obvius & -- & 1 & -- & -- & -- & -- & -- & -- & -- & -- & -- & -- & -- & -- \\
\hline Rheocricotopus & -- & 1 & -- & -- & -- & -- & 1 & -- & -- & -- & -- & -- & -- & -- \\
\hline Synorthocladius semivirens & -- & 1 & -- & -- & -- & -- & -- & -- & -- & -- & -- & -- & -- & -- \\
\hline Tvetenia & -- & 1 & -- & -- & -- & -- & 1 & -- & -- & -- & -- & -- & -- & 1 \\
\hline Bryophaenocladius subvernalis & -- & 1 & -- & -- & -- & -- & -- & -- & -- & -- & -- & -- & -- & -- \\
\hline Chaetocladius & -- & 1 & -- & -- & -- & -- & -- & -- & -- & -- & -- & -- & -- & -- \\
\hline Corynoneura & -- & 1 & -- & -- & -- & -- & -- & -- & -- & -- & -- & -- & -- & -- \\
\hline Epoicocladius ephemerae & -- & -- & -- & -- & 1 & -- & -- & 1 & -- & -- & -- & -- & -- & -- \\
\hline Heleniella ornaticollis & -- & 1 & -- & -- & -- & -- & -- & -- & -- & -- & -- & -- & -- & -- \\
\hline Limnophyes & -- & 1 & -- & -- & -- & -- & -- & -- & -- & -- & -- & -- & -- & -- \\
\hline Metriocnemus & -- & 1 & -- & -- & -- & -- & -- & -- & -- & -- & -- & -- & -- & -- \\
\hline
\end{tabular}


Appendix. Continued.

\begin{tabular}{|c|c|c|c|c|c|c|c|c|c|c|c|c|c|c|}
\hline Taxa & Predator & Grazer & Detritivore & Filterer & Parasite & Sediment & Flow + & Flow- & $\mathrm{N}+$ & N- & $\mathrm{NH}_{3}+$ & $\mathrm{NH}_{3-}^{-}$ & BOD+ & BOD- \\
\hline Parakiefferiella & -- & 1 & -- & -- & -- & -- & -- & -- & -- & -- & -- & -- & -- & -- \\
\hline Parakiefferiella Pel & -- & 1 & -- & -- & -- & -- & -- & -- & -- & -- & -- & -- & -- & -- \\
\hline Parametriocnemus & -- & 1 & -- & -- & -- & -- & -- & -- & -- & -- & -- & -- & -- & -- \\
\hline Paraphaenocladius & -- & 1 & -- & -- & -- & -- & -- & -- & -- & -- & -- & -- & -- & -- \\
\hline Pseudosmittia & -- & 1 & -- & -- & -- & -- & -- & -- & -- & -- & 1 & -- & -- & -- \\
\hline Thienemanniella & -- & 1 & -- & -- & -- & -- & -- & -- & -- & 1 & -- & 1 & -- & 1 \\
\hline Corynoneurella paludosa & -- & 1 & -- & -- & -- & -- & -- & -- & -- & -- & -- & -- & -- & -- \\
\hline Chironomus & -- & -- & 1 & -- & -- & 1 & -- & -- & -- & -- & -- & -- & -- & -- \\
\hline Cladopelma & -- & -- & 1 & -- & -- & 1 & -- & -- & -- & -- & -- & -- & -- & -- \\
\hline Cryptochironomus & 1 & -- & -- & -- & -- & 1 & -- & -- & -- & -- & -- & -- & -- & -- \\
\hline Cryptotendipes & -- & -- & 1 & -- & -- & 1 & -- & -- & -- & -- & -- & -- & -- & -- \\
\hline Demeijerea rufipes & -- & -- & -- & -- & 1 & -- & -- & 1 & -- & -- & -- & -- & -- & -- \\
\hline $\begin{array}{l}\text { Demicryptochironomus } \\
\text { vulneratus }\end{array}$ & 1 & -- & -- & -- & -- & 1 & -- & -- & -- & -- & -- & -- & -- & -- \\
\hline Dicrotendipes nervosus & -- & -- & 1 & -- & -- & 1 & -- & -- & 1 & -- & 1 & -- & 1 & -- \\
\hline Dicrotendipes notatus & -- & -- & 1 & -- & -- & 1 & -- & -- & -- & -- & -- & -- & -- & -- \\
\hline Endochironomus & -- & 1 & -- & -- & -- & -- & -- & 1 & -- & -- & -- & -- & -- & -- \\
\hline Glyptotendipes (ss) & -- & 1 & -- & -- & -- & -- & -- & -- & 1 & -- & 1 & -- & 1 & -- \\
\hline Harnischia & 1 & -- & -- & -- & -- & 1 & -- & -- & -- & -- & -- & -- & -- & -- \\
\hline Kiefferulus tendipediformis & -- & -- & 1 & -- & -- & 1 & -- & -- & -- & -- & -- & -- & -- & -- \\
\hline Microchironomus tener & 1 & -- & -- & -- & -- & 1 & 1 & -- & 1 & -- & -- & -- & -- & -- \\
\hline Microtendipes & -- & -- & 1 & -- & -- & 1 & -- & 1 & -- & 1 & -- & 1 & -- & 1 \\
\hline Parachironomus & -- & -- & -- & -- & 1 & -- & -- & 1 & -- & -- & 1 & -- & 1 & -- \\
\hline Parachironomus frequens & -- & -- & -- & -- & 1 & -- & 1 & -- & -- & -- & -- & 1 & -- & 1 \\
\hline Paralauterborniella nigrohalteralis & -- & -- & 1 & -- & -- & 1 & -- & -- & -- & -- & -- & 1 & -- & -- \\
\hline Paratendipes & -- & -- & 1 & -- & -- & 1 & -- & -- & -- & -- & -- & -- & -- & -- \\
\hline Phaenopsectra & -- & -- & 1 & -- & -- & 1 & -- & -- & -- & -- & -- & -- & -- & -- \\
\hline Polypedilum & -- & -- & 1 & -- & -- & 1 & -- & -- & -- & -- & -- & -- & -- & -- \\
\hline Stictochironomus & -- & -- & 1 & -- & -- & 1 & -- & -- & -- & -- & -- & -- & -- & -- \\
\hline Xenochironomus xenolabis & -- & -- & -- & -- & 1 & -- & -- & 1 & -- & -- & -- & -- & -- & -- \\
\hline Cladotanytarsus & -- & -- & 1 & -- & -- & 1 & -- & -- & -- & -- & -- & -- & -- & -- \\
\hline Micropsectra other & -- & -- & 1 & -- & -- & 1 & -- & -- & -- & -- & -- & -- & -- & -- \\
\hline Micropsectra atrofasciata & -- & -- & 1 & -- & -- & 1 & -- & -- & 1 & -- & 1 & -- & 1 & -- \\
\hline Neozavrelia Pel & -- & 1 & -- & -- & -- & -- & -- & -- & -- & -- & -- & -- & -- & -- \\
\hline Paratanytarsus & -- & 1 & -- & -- & -- & -- & 1 & -- & -- & -- & -- & -- & -- & -- \\
\hline Rheotanytarsus & -- & -- & -- & 1 & -- & -- & 1 & -- & -- & -- & -- & -- & -- & 1 \\
\hline Stempellina almi & -- & 1 & -- & -- & -- & 1 & -- & -- & -- & -- & -- & -- & -- & -- \\
\hline Stempellina bausei & -- & 1 & -- & -- & -- & 1 & -- & -- & -- & -- & -- & -- & -- & -- \\
\hline Stempellinella & -- & 1 & -- & -- & -- & 1 & -- & 1 & -- & -- & -- & -- & -- & -- \\
\hline Tanytarsus & -- & -- & 1 & -- & -- & 1 & -- & -- & -- & -- & -- & -- & -- & -- \\
\hline Tanytarsus brundini & -- & -- & 1 & -- & -- & 1 & -- & -- & -- & 1 & -- & 1 & -- & -- \\
\hline Tanytarsus ejuncidus & -- & -- & 1 & -- & -- & 1 & -- & -- & -- & -- & -- & -- & -- & -- \\
\hline Tanytarsus pallidicornis & -- & -- & 1 & -- & -- & 1 & -- & -- & -- & -- & -- & -- & -- & -- \\
\hline
\end{tabular}

